\title{
Multiple Drug Induced Hypersensitivity Syndrome Reactions in a Patient with Drugs that Have Known HLA Associations for Reactions
}

Khan $\mathbf{S}^{1 *}$, Bhartia $\mathbf{S}^{2}$ and Roy $\mathbf{S}^{1}$

${ }^{1}$ Department of Allergy \& Immunology, Apollo Gleneagles Hospital, Kolkata, West Bengal, India

${ }^{2}$ Department of Haematology \& Bone Marrow Transplantation, Apollo Gleneagles Hospital, Kolkata, West Bengal, India

\begin{abstract}
We report a rare case of a patient with chronic myeloid leukaemia (CML) who had severe drug hypersensitivity reactions with not only allopurinol and imatinib therapies for the $\mathrm{CML}$, but also to a non-steroidal anti-inflammatory drug and an antibiotic. Each of the drugs (allopurinol and imatinib) when used alone, and in combination, had caused various combinations of fever (hyperpyrexia), rash and/or generalized edema. The patient had the HLA-B*58 haplotype that is associated with allopurinol induced Steven-Johnson syndrome. However, in our case, imatinib alone also caused a similar reaction. We discuss the other 'at-risk' HLA alleles and known drug reactions and that our patient was unfortunate to have all of these HLA alleles. Further studies are required to confirm whether the HLA-B*58 haplotype is a risk factor for imatinib induced adverse cutaneous drug reactions.
\end{abstract}

Keywords: Drug hypersensitivity; Imatinib; Allopurinol; HLA

\section{Introduction}

Chronic myeloid leukemia (CML) is considered to be the prototype of the myeloproliferative syndromes. It results from a balanced translocation between chromosomes 9 and $22[\mathrm{t}(9 ; 22)$ the Philadelphia chromosome] creating a unique gene designated $B C R-A B L$, which codes a $210-\mathrm{kDa}$ protein (p210) that functions as a constitutively active tyrosine kinase [1]. Imatinib (Glivec or Gleevec [US], Novartis) blocks tyrosine kinase activity and this therapy has revolutionized not only the treatment of CML, but also of $c-K I T$ D $816 \mathrm{~V}$ mastocytosis, hypereosinophilic syndromes and gastrointestinal stromal tumours where excessive tyrosine kinase signaling leads to the malignancies [2].

However targeted the therapy may be, biologics are not without side effects and Type B (idiosyncratic or 'off target') reactions are possibly the most difficult of them that may necessitate stopping therapy [3].

\section{Case Description}

A 37-year-old female presented with weakness, low grade pyrexia and abdominal distension of 3 weeks duration. On examination, she had pallor and significant splenomegaly. Blood count showed $\mathrm{Hb} 8.6$ $\mathrm{g} / \mathrm{dl}$, white cell count $300,000 / \mathrm{mm}^{3}$ and platelet count $1,12,000 / \mathrm{mm}^{3}$. Bone marrow confirmed the presence of BCR-ABL hybrid transcript with genomic breakpoint e13a2 corresponding to p210 consistent with CML. She was started on allopurinol $300 \mathrm{mg}$ and imatinib 400 mg once daily. 10 days into treatment she had an episode of malena that settled spontaneously. Four weeks after allopurinol and imatinib, she developed high-grade fever, back pain and generalized tiny papular non-itchy eruptions. Imatinib was discontinued but the rash worsened developing into maculo-papular with periorbital edema. Allopurinol was stopped and a course of oral steroids and antihistamine prescribed. A week later the rash (Figure 1a) worsened with glossitis, hyperpyrexia (temperature up to $105^{\circ} \mathrm{F}$ ), difficulty in swallowing and inflamed oral mucosa (Figure 1b). Eosinophilia was observed (baseline absolute eosinophil count was $14 \times 10^{9} / \mathrm{L}$ that increased to maximum $33 \times 10^{9} / \mathrm{L}$ ). There was no source of infection with a normal chest X-Ray and a negative Mantoux test, negative for malaria, typhoid and dengue. Liver function test and renal functions at this stage were normal. It was thought to be DRESS (drug rash, eosinophilia, systemic symptoms) or drug induced hypersensitivity syndrome (DIHS) where inflammatory cytokines lead to fever following drug reaction.

Paracetamol and a single dose of aceclofenac (non steroidal anti-

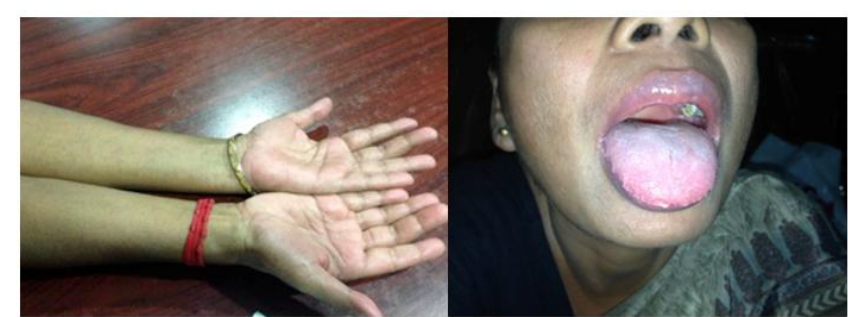

Figure 1: a) Fine maculopapular rash. b) Infmated oral mucosa

inflammatory drug, NSAID) use led to acute renal failure that was managed conservatively with fluids. All medications were stopped at this stage and finally by day 24 her symptoms resolved with normal renal function.

She was managed on hydroxycarbamide and discussed for a plan to restart on low dose imatinib. At home, the patient inadvertently took allopurinol instead of pantoprazole and developed a faint rash with generalized edema that fortunately settled in a few days. A re-challenge with imatinib led to recurrence of edema, hyperpyrexia, vomiting and mouth ulcers.

Delay in treatment due to these drug reactions led to myeloid blast crisis. Clavam (Amoxicillin, Clavulanic acid) was started for a respiratory infection but she was unable to tolerate this due to severe vomiting. After several discussions regarding available treatment options, she was started on an alternate tyrosine kinase inhibitor, dasatinib, which she fortunately tolerated quite well for about 2 weeks. However, severe thrombocytopenia led to profuse intra-abdominal

${ }^{*}$ Corresponding author: Sujoy Khan, Consultant Immunologist, Apollo Gleneagles Hospital, 58, Canal Circular Road, Kolkata, West Bengal, India, Tel: +91 (0) 33 2320 2122; Fax: +91 (0) 222320 5218; E-mail: sujoykhan@gmail.com

Received January 04, 2014; Accepted February 27, 2014; Published March 15 2014

Citation: Khan S, Bhartia S, Roy S (2014) Multiple Drug Induced Hypersensitivity Syndrome Reactions in a Patient with Drugs that Have Known HLA Associations for Reactions. Gen Med (Los Angel) 2: 133. doi: 10.4172/2327-5146.1000133

Copyright: ( 2014 Khan S, et al. This is an open-access article distributed under the terms of the Creative Commons Attribution License, which permits unrestricted use, distribution, and reproduction in any medium, provided the original author and source are credited. 


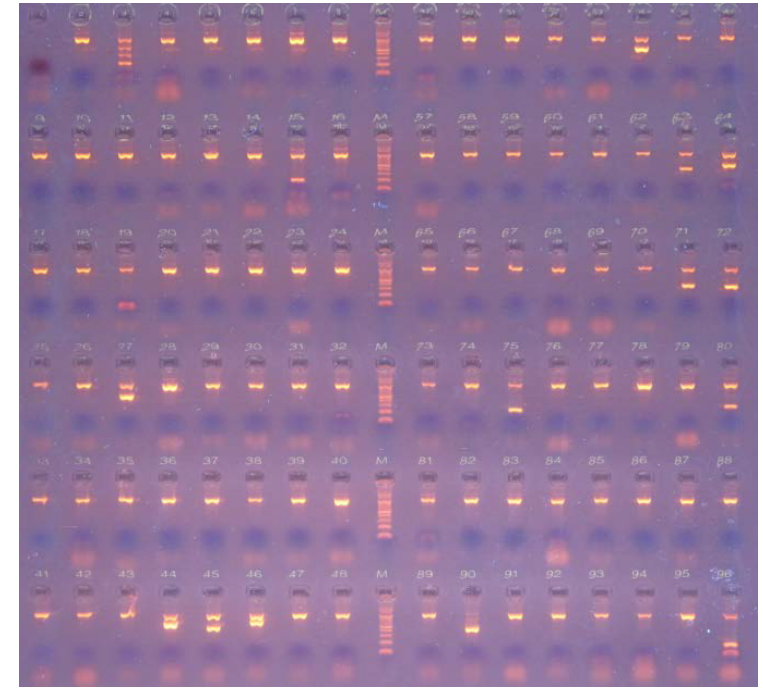

Figure 2: HLAABDR typing gel (well no 1, contamination control; well nos 2-24 pre-coated primers for HLA-A alleles; well nos 25-72 pre-coated primers fo HLA-B alleles and well nos 73-96 correspond to pre-coated primers for HLADR alleles) with internal control (IC) band for all wells at $1070 \mathrm{bp}$. The HLA type of the patient was HLA-A*02, $A^{*} 02$; HLA-B*40, $B^{*} 58$; HLA$\mathrm{DR}^{*} 07, \mathrm{DR}^{*} 15$ with HLA-DRB4 and HLA-DRB5

bleeding and she could not be resuscitated at another private hospital.

HLA ABDR sequence specific primer typing was done via low resolution PCR from DNA extracted from $200 \mu \mathrm{L}$ EDTA whole blood by spin protocol using QiaAMP DNA Mini kit 50 (Qiagen), using the ABDR Histotype kit (BAG Health Care GmbH, Germany). The patient was found to be HLA- $\mathrm{B}^{\star} 58$ positive with lane corresponding to primer extending for HLA- $B^{\star}$ 58:01 (gel picture interpreted with HLA haplotype, Figure 2). The HLA type of the patient was:

HLA- $A^{\star} 02$, HLA-A ${ }^{\star} 02$; HLA-B ${ }^{\star} 40, \quad$ HLA $^{\star}{ }^{\star} 58, \quad$ HLA-DR ${ }^{\star} 07$, HLA-DR ${ }^{\star} 15$ and positive for HLA-DRB4 and HLA-DRB5

\section{Discussion}

Our patient had multiple drug hypersensitivity syndrome (MDHS) like reactions to several drugs, almost all of which have known HLA associations. There are two subtypes of MDHS, as suggested by Pichler and colleagues where one develops against different drugs given simultaneously (first subtype), and the second subtype in which the sensitisations develop sequentially, sometimes years apart [4-9]. One would consider that our patient belongs to the first subtype, but the subsequent 'sensitizations' to unrelated drugs also indicates that the second subtype is present (i.e., mixed phenotype). She not only initially reacted to allopurinol and imatinib but subsequently also to a NSAID and penicillin group of drugs. Whilst the HLA association is highest for allopurinol-induced reactions [10], the association with NSAID and penicillins is not that strong, and incidentally our patient had inherited the 'at-risk' HLA alleles that may have led to these severe reactions. Financial constraints prevented us from doing an exhaustive Specific IgE-based drug tests, regulatory $\mathrm{T}$ cell levels [5] or the Flow-assisted basophil activation assays.

This raises the moral/ethical question into whether clinicians should consider pre-testing selective patients for genetic variants to avoid unwarranted drug side effects. Two of these serious drug reactions is Stevens-Johnson syndrome/Toxic epidermal necrolysis (SJS/TEN) and Drug Rash, Eosinophilia and Systemic Symptoms (DRESS, or also referred to as DIHS). The estimated occurrence of DRESS is between 1 in 1000 to 1 in 10,000 drug exposures [10,11]. Several commonly used drugs cause SJS or DRESS/DHS with the antiepileptic carbamazepine being the worst culprit, and not uncommonly lamotrigine, phenobarbital, sulfasalasine including allopurinol [12]. Our case fulfilled the major European (RegiSCAR, Kardaun 2007) and Japanese (Shiohara 2007) criteria for DRESS (Table 1). Allopurinol is widely used as concomitant therapy to prevent chemotherapy induced tumour lysis and hyperuricaemia. Studies have confirmed a strong and significant association between HLA-B ${ }^{\star} 5801$ and allopurinol induced severe skin reactions such as Steven Johnson syndrome or toxic epidermal necrolysis [12-14]. The HLA-B ${ }^{\star} 58$ haplotype frequency in Asian populations is estimated at $6 \%$, and therefore it may be justified to screen for this haplotype if allopurinol is absolutely required. Other allopurinol-induced skin reactions such as hypersensitivity vasculitis, vesiculo bullous dermatitis, exfoliative dermatitis, pruritis, urticaria, lichen planus have been reported [14].

Up to $90 \%$ of patients experience skin rashes and a non-allergic periorbital edema with imatinib therapy [15]. Rashes are frequently pruritic and most commonly appear as erythematous, maculopapular lesions on forearms, trunk, and less frequently on the face. Hyperpyrexia, as seen in our patient, has been described in another report [16], including Steven Johnson syndrome with imatinib and allopurinol [17] and DRESS with imatinib [18,19]. Skin biopsies reveal the typical appearance of a toxic drug reaction with a mixed cellular infiltrate. Mild reactions (rash only) can be easily managed with antihistamines or topical steroids. Severe rashes with desquamative components $(<1 \%$ of cases) are managed with immediate discontinuation of therapy and institution of systemic steroids $(1 \mathrm{mg} / \mathrm{kg} /$ day $)$. Imatinib can be started at $100 \mathrm{mg} /$ day, with dose increased by $100 \mathrm{mg} /$ week while tapering the steroids, provided there is no recurrence of rash and no other treatment option exists other than imatinib. No reports exist until date on the HLA haplotype and risk of imatinib skin reactions. Although sensitivity to other tyrosine kinase inhibitors remains a possibility in these patients [20-25], our patient had no reaction for the two weeks on dasatinib suggesting (1) clinical cross reactivity to all tyrosine kinase inhibitors is not absolute; (2) the purported HLA-peptide presentation, if at all HLA-B ${ }^{\star 58: 01}$ is for imatinib, is not same for all tyrosine kinase

\begin{tabular}{l}
\hline Hospitalization \\
\hline Reaction suspected to be drug-related \\
\hline Acute rash* \\
\hline Fever $>38^{\circ} \mathrm{C}^{*}$ \\
\hline Lymphadenopathy in at least two sites \\
\hline Involvement of at least one internal organ* \\
\hline $\begin{array}{l}\text { Blood count abnormalities } \\
\text { (lymphopenia or lymphocytosis*, eosinophilia*, thrombocytopenia* }\end{array}$ \\
\hline a. RegiSCAR inclusion criteria 3 of the 4 starred criteria required for diagnosis \\
\hline Maculopapular rash developing $>3$ weeks after starting the suspected drug \\
\hline Prolonged clinical symptoms 2 weeks after discontinuation of the suspected drug \\
\hline Fever $>38^{\circ} \mathrm{C}$ \\
\hline Liver abnormalities (ALT $>100$ U/L) or other organ involvement \\
\hline Leukocyte abnormalities \\
\hline Leukocytosis ( $\left.>11 \times 10^{\circ} / L\right)$ \\
\hline Atypical lymphocytosis (>5\%) \\
\hline Lymphadenopathy \\
\hline HHV-6 reactivation \\
\hline
\end{tabular}

b. Japanese consensus group criteria for DRESS/DIHS

Seven criteria required for diagnosis or first five for atypical DRESS Table 1: DRESS/DIHS diagnostic criteria. 


\begin{tabular}{|c|c|c|c|c|}
\hline Drug & Reactions & HLA-B Allele & Population & References \\
\hline $\begin{array}{l}\text { Carbamazepine } \\
\text { (anti-epileptic) }\end{array}$ & $\begin{array}{l}\text { SJS/TEN } \\
\text { Odds Ratio }(O R)=97.6\end{array}$ & $B^{*} 15: 02$ & $\begin{array}{l}\text { Han Chinese, Thai, Malay, } \\
\text { Indian }\end{array}$ & $\begin{array}{l}\text { Hsiao YH, } 2013 \text { [26]; } \\
\text { Ding, } 2010 \text { [27] } \\
\text { Tasseneeyakul, 2010 [28]; } \\
\text { Wu XT, } 2010 \text { [29] }\end{array}$ \\
\hline $\begin{array}{l}\text { Allopurinol } \\
\text { (uricosuric agent) }^{\S}\end{array}$ & $\begin{array}{l}\text { SJS/TEN } \\
\text { OR }=85.36 \\
\text { DIHS/DRESS } \\
\text { OR }=99.59\end{array}$ & $B * 58: 01$ & $\begin{array}{l}\text { Han Chinese, Thai, Japanese, } \\
\text { Malay }\end{array}$ & $\begin{array}{l}\text { Goncalo M, 2013 [12]; } \\
\text { Ding, 2010 [27]; } \\
\text { Kaniwa, } 2008 \text { [30] }\end{array}$ \\
\hline $\begin{array}{l}\text { Abacavir } \\
\text { (Anti-retroviral) }\end{array}$ & DIHS/DRESS & $B^{*} 57: 01$ & Caucasians & $\begin{array}{l}\text { Martin, } 2004[31] ; \\
\text { Mallal, } 2008 \text { [32] }\end{array}$ \\
\hline $\begin{array}{l}\text { Lamotrigine } \\
\text { (anti-epileptic) }\end{array}$ & DIHS/DRESS & $B^{*} 58: 01$ & Caucasians & Kazeem, 2009 [33] \\
\hline Flucloxacillin & Liver Toxicity & $B * 57: 01$ & Caucasians & Kostenko, 2011 [34] \\
\hline Oxicam (NSAID) $)^{\S}$ & SJS/TEN & $\mathrm{A} 2, \mathrm{~B} * 73$ & Caucasians & $\begin{array}{l}\text { Roujeau, } 1987 \text { [35] } \\
\text { Lonjou, } 2008 \text { [36] }\end{array}$ \\
\hline Sulphamethoxazole & SJS/TEN & $\mathrm{A} 29, \mathrm{~B}^{*} 38, \mathrm{~B} 12, \mathrm{DR} 7^{\$}$ & Caucasians & Lonjou, 2008 [36] \\
\hline Co-amoxiclav $\$$ & $\begin{array}{l}\text { Hepatotoxicity } \\
\mathrm{OR}=2.56\end{array}$ & DRB1*15 & Caucasians & Donaldson, 2010 [37] \\
\hline
\end{tabular}

Table 2: The known 'at-risk' HLA-B alleles [including the alleles in our patient $\left({ }^{\S}\right)$ ] associated with severe adverse drug reactions.

inhibitor group of drugs and (3) patients should be offered an alternative drug even though MDHS/DIHS was an issue with the alternative drug falling under the same category or generic version of the drug.

Our patient had inherited several 'at-risk' HLA alleles for severe drug reactions (Table 2 outlines the drugs and HLA alleles associated with DIHS), [26-37]. It is possible that herpes virus reactivation, most notably HHV-6, was the common underlying factor for the multiple drug reactions [38-42], although that was not proven in our case. We conclude that the HLA-B ${ }^{\star} 58$ haplotype may be a risk factor for drug hypersensitivity syndrome with imatinib therapy in patients who react to allopurinol, but this needs to be confirmed in further studies. Clinicians should be aware of the already identified 'high-risk HLA alleles' for adverse reactions to commonly used drugs, and how to counsel such patients.

\section{References}

1. Sawyers CL (1999) Chronic myeloid leukemia. N Engl J Med 340: 1330-1340.

2. Schiffer CA (2007) BCR-ABL tyrosine kinase inhibitors for chronic myelogenous leukemia. N Engl J Med 357: 258-265.

3. Sathish JG, Sethu S, Bielsky MC, de Haan L, French NS, et al. (2013) Challenges and approaches for the development of safer immunomodulatory biologics. Nat Rev Drug Discov 12: 306-324.

4. Gex-Collet C, Helbling A, Pichler WJ (2005) Multiple drug hypersensitivity-proof of multiple drug hypersensitivity by patch and lymphocyte transformation tests. J Investig Allergol Clin Immunol 15: 293-296.

5. Daubner B, Groux-Keller M, Hausmann OV, Kawabata T, Naisbitt DJ, et al. (2012) Multiple drug hypersensitivity: normal Treg cell function but enhanced in vivo activation of drug-specific T cells. Allergy 67: 58-66.

6. Lehloenya RJ, Wallace J, Todd G, Dheda K (2012) Multiple drug hypersensitivity reactions to anti-tuberculosis drugs: five cases in HIV-infected patients. Int J Tuberc Lung Dis 16: 1260-1264.

7. Chiriac AM, Demoly P (2013) Multiple drug hypersensitivity syndrome. Curr Opin Allergy Clin Immunol 13: 323-329.

8. Voltolini S, Bignardi D, Minale P, Pellegrini S, Troise C (2009) Phenobarbitalinduced DiHS and ceftriaxone hypersensitivity reaction: a case of multiple drug allergy. Eur Ann Allergy Clin Immunol 41: 62-63.

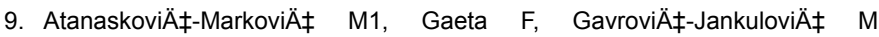

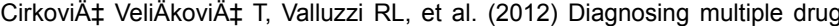
hypersensitivity in children. Pediatr Allergy Immunol 23: 785-791.

10. Camous X, Calbo S, Picard D, Musette P (2012) Drug Reaction with Eosinophilia and Systemic Symptoms: an update on pathogenesis. Curr Opin Immunol 24: 730-735.
11. Criado PR, Avancini J, Santi CG, Medrado AT, Rodrigues CE, et al. (2012) Drug reaction with eosinophilia and systemic symptoms (DRESS): a complex interaction of drugs, viruses and the immune system. Isr Med Assoc J 14: 577 582

12. Gonçalo M, Coutinho I, Teixeira V, Gameiro AR, Brites MM, et al. (2013) HLA-B*58:01 is a risk factor for allopurinol-induced DRESS and StevensJohnson syndrome/toxic epidermal necrolysis in a Portuguese population. $\mathrm{Br} \mathrm{J}$ Dermatol 169: 660-665.

13. Kwok J, Kwong KM (2013) Detection of HLA-B*58:01, the susceptible allele for allopurinol-induced hypersensitivity, by loop-mediated isothermal amplification. $\mathrm{Br} J$ Dermatol 168: 526-532.

14. Ramasamy SN, Korb-Wells CS, Kannangara DR, Smith MW, Wang N, et al. (2013) Allopurinol hypersensitivity: a systematic review of all published cases, 1950-2012. Drug Saf 36: 953-980.

15. Barbaud A, Granel F, Waton J, Poreaux C (2011) How to manage hypersensitivity reactions to biological agents? Eur J Dermatol 21: 667-674

16. Huang X, Patel S, Ahmed N, Seiter K, Liu D (2009) Severe toxicity of skin rash, fever and diarrhea associated with imatinib: case report and review of skin toxicities associated with tyrosine kinase inhibitors. Drug Des Devel Ther 2: 215-219.

17. Hsieh HJ, Chan AL, Lin SJ (2009) Stevens-Johnson syndrome induced by combination of imatinib and allopurinol. Chemotherapy 55: 197-199.

18. Goldman J, Duval-Modeste AB, Lambert A, Contentin N, Courville P, et al. (2008) [Imatinib-induced DRESS]. Ann Dermatol Venereol 135: 393-396.

19. Le Nouail P, Viseux V, Chaby G, Billet A, Denoeux JP, et al. (2006) [Drug reaction with eosinophilia and systemic symptoms (DRESS) following imatinib therapy]. Ann Dermatol Venereol 133: 686-688.

20. Faye E, Bondon-Guitton E, Olivier-Abbal P, Montastruc JL (2013) French Network of Regional Pharmacovigilance Centers. Spontaneous reporting of serious cutaneous reactions with protein kinase inhibitors. Eur J Clin Pharmacol 69: 1819-1826.

21. Brazzelli V, Grasso V, Borroni G (2013) Imatinib, dasatinib and nilotinib: a review of adverse cutaneous reactions with emphasis on our clinical experience. J Eur Acad Dermatol Venereol 27: 1471-1480.

22. Breccia M, Alimena G (2013) Occurrence and current management of side effects in chronic myeloid leukemia patients treated frontline with tyrosine kinase inhibitors. Leuk Res 37: 713-720.

23. Amitay-Laish I, Stemmer SM, Lacouture ME (2011) Adverse cutaneous reactions secondary to tyrosine kinase inhibitors including imatinib mesylate, nilotinib, and dasatinib. Dermatol Ther 24: 386-395.

24. Novitzky-Basso I, Craddock C (2011) Cross-intolerance to imatinib, dasatinib and nilotinib therapy in a patient with chronic myeloid leukaemia. Eur Haematol 86: 548-549.

25. Lamchahab M, Qachouh M, Hali F, Benchikhi H, Quessar A, et al. (2012) 
Citation: Khan S, Bhartia S, Roy S (2014) Multiple Drug Induced Hypersensitivity Syndrome Reactions in a Patient with Drugs that Have Known HLA Associations for Reactions. Gen Med (Los Angel) 2: 133. doi: 10.4172/2327-5146.1000133

[Successive cutaneous adverse reactions to nilotinib and imatinib in a single patient]. Ann Dermatol Venereol 139: 828-831.

26. Hsiao YH, Hui RC, Wu T, Chang WC, Hsih MS, et al. (2014) Genotype-phenotype association between $\mathrm{HLA}$ and carbamazepine-induced hypersensitivity reactions: Strength and clinical correlations. J Dermatol Sci 73: 101-109.

27. Ding WY, Lee CK, Choon SE (2010) Cutaneous adverse drug reactions seen in a tertiary hospital in Johor, Malaysia. Int J Dermatol 49: 834-841.

28. Tassaneeyakul W1, Tiamkao S, Jantararoungtong T, Chen P, Lin SY, et al. (2010) Association between HLA-B*1502 and carbamazepine-induced severe cutaneous adverse drug reactions in a Thai population. Epilepsia 51: 926-930.

29. Wu XT, Hu FY, An DM, Yan B, Jiang X, et al. (2010) Association between carbamazepine-induced cutaneous adverse drug reactions and the HLA-B*1502 allele among patients in central China. Epilepsy Behav 19: 405408.

30. Kaniwa N, Saito $Y$, Aihara M, Matsunaga K, Tohkin M, et al. (2008) JSAR research group. HLA-B locus in Japanese patients with anti-epileptics and allopurinol-related Stevens-Johnson syndrome and toxic epidermal necrolysis. Pharmacogenomics 9: 1617-1622.

31. Martin AM, Nolan D, Gaudieri S, Almeida CA, Nolan R, et al. (2004) Predisposition to abacavir hypersensitivity conferred by HLA-B ${ }^{\star} 5701$ and a haplotypic Hsp70-Hom variant. Proc Natl Acad Sci U S A 101: 4180-4185.

32. Mallal S, Phillips E, Carosi G, Molina JM, Workman C, et al. (2008) HLA-B*5701 screening for hypersensitivity to abacavir. N Engl J Med 358: 568-579.

33. Kazeem GR, Cox C, Aponte J, Messenheimer J, Brazell C, et al. (2009) High-resolution HLA genotyping and severe cutaneous adverse reactions in lamotrigine-treated patients. Pharmacogenet Genomics 19: 661-665.

34. Kostenko L, Kjer-Nielsen L, Nicholson I, Hudson F, Lucas A, et al. (2011) Rapid screening for the detection of HLA-B57 and HLA-B58 in prevention of drug hypersensitivity. Tissue Antigens 78: 11-20.

35. Roujeau JC, Huynh TN, Bracq C, Guillaume JC, Revuz J, et al. (1987) Genetic susceptibility to toxic epidermal necrolysis. Arch Dermatol 123: 1171-1173.

36. Lonjou C, Borot N, Sekula P, Ledger N, Thomas L, et al. (2008) A European study of HLA-B in Stevens-Johnson syndrome and toxic epidermal necrolysis related to five high-risk drugs. Pharmacogenet Genomics 18: 99-107.

37. Donaldson PT, Daly AK, Henderson J, Graham J, Pirmohamed M et al. (2010) Human leucocyte antigen class II genotype in susceptibility and resistance to co-amoxiclav-induced liver injury. J Hepatol 53: 1049-1053.

38. Debarbieux S, Deroo-Berger MC, Grande S, Najioullah F, Kanitakis J, et al. (2006) [Drug hypersensitivity syndrome associated with a primary HHV6 infection]. Ann Dermatol Venereol 133: 145-147.

39. Descamps V, Bouscarat F, Laglenne S, Aslangul E, Veber B, et al. (1997) Human herpesvirus 6 infection associated with anticonvulsant hypersensitivity syndrome and reactive haemophagocytic syndrome. Br J Dermatol 137:605608.

40. Aouam K, Bel Hadj Ali H, Youssef M, Chaabane A, Amri M, et al. (2008) Carbamazepine-induced DRESS and HHV6 primary infection: the importance of skin tests. Epilepsia 49: 1630-1633.

41. Hashizume H, Fujiyama T, Kanebayashi J, Kito Y, Hata M, et al. (2013) Skin recruitment of monomyeloid precursors involves human herpesvirus-6 reactivation in drug allergy. Allergy 68: 681-689.

42. Saraya T, Mikoshiba M, Kamiyama $H$, Yoshizumi $M$, Tsuchida $S$, et al. (2013) Evidence for reactivation of human herpesvirus 6 in generalized lymphadenopathy in a patient with drug-induced hypersensitivity syndrome. $J$ Clin Microbiol 51: 1979-1982. 